\title{
Studies on Attituide of Staff Nurses Regarding Their Legal Responsibilities in Selected Hospitals of J\&K State
}

\author{
Authors \\ Rifat Haffiz ${ }^{1}$, Nighat Haffiz Reshi ${ }^{2}$, Santosh Kaur $^{3}$, Shugufta Maqbool ${ }^{4}$ \\ ${ }^{1}$ Nursing Supervisor, SKIMS Medical College and Hospital, Srinagar, J\&K \\ ${ }^{2}$ Assistant Professor, Government College of Nursing, GMC, Srinagar, J\&K \\ ${ }^{3}$ Associate Professor, MM. College of Nursing, SKIMS Srinagar, J\&K \\ ${ }^{4}$ Tutor, Ancillary medical training (AMT), School, Kangan Ganderbal, J\&K
}

\begin{abstract}
To find out the attitude of staff nurses regarding their legal responsibilities in some selected hospitals of Jammu and Kashmir State, sixty numbers of subjects (nurses) were questioned by simple random sampling technique was employed to select the sample subjects. A structured knowledge questionnaire with 39 knowledge items was developed for the study. Content validity of the tools and information booklet was established by 9 experts. Reliability was established by KR 20 method and the tool was found reliable with reliability coefficient of 0.7 . The reliability of the attitude questionnaire was established by test retest method which was found to be 0.85.The data collected was analyzed using both descriptive and inferential statistics. From the study it was found that majority (74\%) of the staff nurses belonged to the age group of $30-40$ years. $46 \%$ \& $44 \%$ of the staff nurses' professional education were post-basic BSc. Nursing and GNM respectively. Majority (88\%) of the staff nurses had a working experience of 10-15 years. Majority $(80 \%)$ of the staff nurses had not attended in-service education programme the mean pre test attitude score is 150.44.with a median 155 and SD 14.465 against the maximum score 210. The mean post-test attitude score is 186 with a median of 184 and SD 13.464 against a maximum score of 210. Mean post-test attitude scores 186 of staff nurses were found to be significantly higher than their mean pre-test attitude scores 150.44 as evident from the ' $t$ ' value of 12.858 was significant., suggesting the effectiveness of booklet in adopting the positive attitude by staff nurses' on legal responsibilities.

Key words: legal responsibilities, information booklet, staff nurses, attitude
\end{abstract}

\section{Introduction}

Nurses constitute the largest workforce of professionals working in any health care setting. Their presence in the health care system plays a vital role and helps in the speedy recovery of the patients from their illness. In the recent times, legal liability and accountability of professional nursing conduct has emerged as an urgent concern, and the practicing nurses face legal issues very often. These issues may be in connection to negligence in conduct and advocating for the patient. If these duties and 
regulations are not followed and a positive attitude is not developed, the nurse is at risk of losing his/her license and facing a malpractice suit.

It differentiates nursing attitude and practice from that of other health care professions and describes and protects the rights of clients as well as nurses. For these reasons, the nurses should have an understanding of the basic legal concepts as they relate to nursing practice. The role of professional nurse has changed in a pragmatic sense from that of the legal dependency to legal accountability.

Health Law is the federal, state, and local law, rules, regulations and other jurisprudence affecting the health care industry and their application to health care providers, patients and payers, and vendors to the health care industry, including without limiting the (1) relationships among providers, payers and vendors to the health care industry and its patients and (2) delivery of health care services with an emphasis on operations, regulatory and transactional legal issues.

\section{OBJECTIVES}

- To develop information booklet on legal responsibilities for nurses and health care workers.
- To study the attitude of staff nurses related to legal responsibilities before the administration of information booklet.

- To study the attitude of staff nurses related to legal responsibilities after the administration of information booklet.

- To find out the relationship between the attitude of staff nurses and selected demographic factors- (Age, Professional qualification ,Clinical experience)

The conceptual frame work for the study was based on systems model. The experimental research approach with one group pre-test and post test design was used. Simple random sampling technique was employed to select the sample subjects. A structured knowledge questionnaire with 39 knowledge items

Content validity of the tools and information booklet was established by 9 experts. Reliability was established by KR 20 method and the tool was found reliable with reliability Coefficient of 0.7 .The reliability of the attitude questionnaire was established by test retest method which was found to be 0.85 .

The data collected was analyzed using both descriptive and inferential statistics.

Summary of findings in tabular form as given below:

Table-1 Frequency and percentage distribution of staff nurses by demographic characteristics $\mathrm{n}=50$

\begin{tabular}{|c|l|l|l|}
\hline S/no & Socio-demographic variables & Frequency & Percentage $(\%)$ \\
\hline 1. & Age (in years) & & \\
& $\bullet 20-30$ & 00 & 00 \\
& $\bullet 31-40$ & 37 & 74 \\
& $\bullet \quad$ Above 40 & 13 & 26 \\
\hline 2. & Gender & 00 & \\
& $\bullet \quad$ Male & 50 & 00 \\
& $\bullet \quad$ Female & 44 & 100 \\
\hline 3. & Marital status & 06 & 88 \\
& $\bullet$ Married & & 12 \\
\hline 4. & Professional qualification & 46 \\
& $\bullet$ GNM & 22 & 44 \\
\hline
\end{tabular}




\begin{tabular}{|c|l|l|l|}
\hline & $\bullet \quad$ B.Sc Nursing & 05 & 10 \\
\hline 5. & Clinical experience(years) & & \\
& $\bullet 2-5$ & 00 & 00 \\
& $\bullet 6-10$ & 04 & 8 \\
& $\bullet 11-15$ & 44 & 88 \\
& $\bullet \quad$ Above 15 & 02 & 04 \\
\hline 6. & In-service education programme & & \\
& attended, if any & 40 & 80 \\
& $\bullet \quad$ No & 10 & 20 \\
\hline & Yes & \\
\hline
\end{tabular}

The data presented in table 1 indicates that:

- Majority of staff nurses $37(74 \%)$ were in the age group of 31-40 years, followed by $13(26 \%)$ in the age group of $31-40$ years.

- All the study subjects 50(100\%) were females.

- Majority of study subjects $44(88 \%)$ were married and only 6(12\%) were unmarried.

- Majority of the subject's 23 (46\%) were GNM and 22 (44\%) were post basic B Sc and only 5 (10\%) were basic B Sc nursing.
- Majority of staff nurses $44(88 \%)$ had a working experience of 11-15 years whereas $4(8 \%)$ staff nurses had 6-10 years and 2( $4 \%$ ) has more than 15 years of clinical experience in field of nursing.

- Majority of the study subjects $40(80 \%)$ had attended in-service programme and only $10(20 \%)$ has not attended any inservice education programme.

TABLE 2 Mean, Mean difference, standard deviation, of pre test and post test attitude scores of staff nurses $\mathrm{n}=50$

\begin{tabular}{|l|l|l|l|l|l|}
\hline $\begin{array}{l}\text { Attitude } \\
\text { score }\end{array}$ & $\begin{array}{l}\text { Range of } \\
\text { obtained score }\end{array}$ & Mean & $\begin{array}{l}\text { Mean } \\
\text { difference }\end{array}$ & Median & S.D \\
\hline Pre-test & $111-171$ & 150.44 & 35.66 & 155 & 14.46 \\
\cline { 5 - 6 } & Post-Test & $171-210$ & 186.10 & 184.00 & 13.46 \\
\hline
\end{tabular}

\section{Maximum possible score $=\mathbf{2 1 0}$}

The table 2 shows that the mean post test attitude scores of staff nurses (186.10) was higher than their mean pre test attitude scores (150.44). The pre-test attitude scores of the staff nurses

ranged from 111 to 171 with a mean of 150.44 median of 155 . The post-test attitude scores ranged from 171 to 210 with mean 186.10 and median of 184 .

Table 3 Mean; Mean percentage of pre-test and post-test attitude scores obtained by Staff nurses on Legal Responsibilities $\mathrm{n}=50$

\begin{tabular}{|l|l|l|l|}
\hline $\begin{array}{l}\text { Attitude Test } \\
\text { Scores }\end{array}$ & Mean & Mean \% score & Mean \% Gain \\
\cline { 1 - 3 } Pre-test & 150.44 & 71.64 & $16.93 \%$ \\
\cline { 1 - 3 } Post-test & 186.10 & 88.57 & \\
\hline
\end{tabular}

Maximum score $=210$ 
The Data presented in table 3 shows the mean percentage gain (16.93) scores when compares with the mean pre-test and mean post test attitude scores.

The mean percentage attitude scores was computed by dividing mean of pre-test, post test attitude scores .Maximum possible scores,
(210) and multiplying the ratio by hundred The difference between the mean post test percentage scores and mean pre-test scores indicates the mean percentage gain scores. The attitude gain scores indicate the effectiveness of information booklet.

Table-4 Mean, mean difference, pre-test and post-test attitude scores and ' $p$ ' value $n=50$

\begin{tabular}{|l|l|l|l|l|}
\hline Attitude test & Mean \pm S.D & Mean difference & 't' value & ' $p$ ' value \\
\hline Pre-test & 150.44 & \multirow{2}{*}{35.66} & -12.858 & $<0.001^{*}$ \\
\hline Post-test & 186.10 & & & \\
\cline { 1 - 2 }
\end{tabular}

*Significant at $1 \%$ level of significance.

Maximum possible scores $=\mathbf{2 1 0}$

The Data presented in table 4 shows that the mean post test attitude scores (186.10) of staff nurses related to legal responsibilities of nurses was higher than mean pre-test attitude scores (150.10). The obtained mean difference was 35.66 between pre-test and post-test attitude. The obtained mean difference scores was found to be statistically significant as evident from the ' $p$ ' value $<0.001$. Therefore, the obtained mean difference was a true difference and it was not by chance .Hence the null Hypothesis $\left(\mathrm{Ho}_{2}\right)$ was rejected and research hypothesis $\left(\mathrm{H}_{2}\right)$ was accepted.

Table-5 Level of attitude Scores of staff nurses regarding legal responsibilities. $\mathrm{n}=50$

\begin{tabular}{|l|l|l|l|}
\hline & Level of Scores & $\begin{array}{l}\text { Pretest } \\
\text { Frequency }\end{array}$ & $\begin{array}{l}\text { Post test } \\
\text { Frequency }\end{array}$ \\
\hline \multirow{3}{*}{ Attitude } & Adequate & 21 & 45 \\
\cline { 2 - 4 } & Inadequate & 29 & 5 \\
\hline
\end{tabular}

Attitude

Adequate Score $\geq 70 \%$

Inadequate Score $<70 \%$

Maximum possible Attitude score $=210$

Data presented in table 5 indicates that the attitude scores in pre test was inadequate in 29 subjects before the administration of booklet which

increased to adequate knowledge in 45 of the staff nurses after the administration of the information booklet.

Table 6 Level of attitude scores of Staff Nurses Regarding Legal responsibilities. $\mathrm{n}=50$

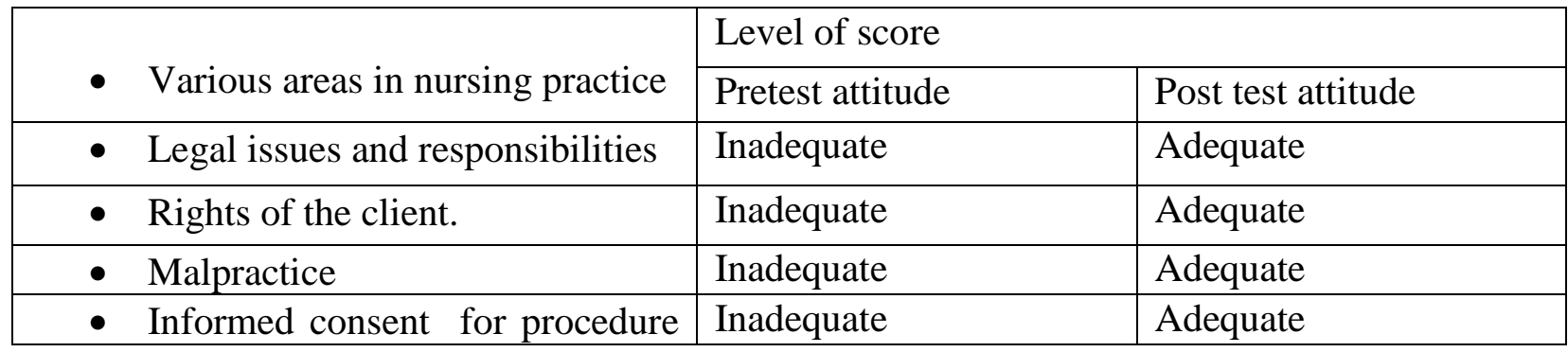




\begin{tabular}{|l|l|l|}
\hline and Surgery & & \\
\hline$\bullet$ Administration of medication & Adequate & Adequate \\
\hline$\bullet$ Documentation & Adequate & Adequate \\
\hline$\bullet$ Confidentiality & Inadequate & Adequate \\
\hline
\end{tabular}

Maximum possible Scores $=\mathbf{2 1 0}$

Adequate Score $\geq 70 \%$

Inadequate Score $<70 \%$

The Data presented in table 6 shows that the level of attitude of staff nurses in areas of Administration of medication and Documentation was adequate whereas in rest of the areas i.e. in, Legal issues and responsibilities, Rights of the client, Malpractice, Informed Consent and, Confidentiality areas the level of attitude was inadequate in the pretest.

In the post test the staff nurses showed adequate level of attitude scores in all the six areas. This shows that the booklet was effective in increasing the level of attitude in the Staff nurses.

\section{DISCUSSION OF THE FINDINGS}

Findings of the present study have been discussed in terms of objectives, theoretical basis and hypothesis. In this session major findings of present study have been discussed with reference to the results obtained by other investigators. The present study was aimed at identifying knowledge and attitude of staff nurses, regarding legal responsibilities of nurses.

The findings conducted by Aveyard, H (2010) to find out the way nurses take consent of patient before the procedures also showed that there was no significant relationship of knowledge and practice of staff nurses with selected factors. The study conducted by Barnbas's (2004) revealed the same findings. She found relationship of knowledge and in-service education does play an important role in the enhancement of the knowledge.

Present study results also revealed that the staff nurses had less knowledge before administration of information booklet and there was a significant gain in knowledge after the administration of Information booklet regarding legal responsibilities. The findings of the study are consistent with the study done by Prema Paul (2009) to evaluate the effectiveness of information booklet on legal responsibilities of staff nurses. She also mentioned that $86 \%$ of nurses believed that information booklet was a good source of learning.

\section{IMPLICATIONS}

Implications for nursing attitude:

It is crucial to be aware of changes in the laws that affect nursing attitude and the health care delivery system. The knowledge about of the study legal aspects in nursing is essential for each nurse to safeguard self and clients from legal problems.

\section{NURSING ADMINISTRATION}

Regular supervision in terms identifying the areas that require emphasis, and correction of the subordinates should be done. Job orientation by supervisors and problem solving approach of the hospital administrator or supervisors should be done.

Appropriate teaching -learning materials need to be prepared and made available for staff nurses. A separate nurse can be appointed to see the legal issues \& give consultations wherever needed by the nursing professionals in the hospital.

\section{NURSING EDUCATION}

Nursing curricula should equip students with knowledge on legal responsibilities and include chapters on legal aspects to prepare the good nurses in future. There should be adequate guidance, supervision and evaluation of nursing students in the clinical areas regarding legal responsibilities. 


\section{NURSING RESEARCH}

Nursing research should be encouraged as to prepare various educational materials related to legal responsibilities for staff nurses and evaluate their effectiveness. Very less studies are done on legal aspects in nursing, therefore there is need to conduct more research studies in the field of various legal aspects.

There is need to conduct further research in this context. This will help in identifying the problems as well as provide information, regarding nursing attitude related to legal response.

\section{SUMMARY AND CONCLUSION OF THE STUDY}

All nurses should be familiar with nursing law and ethics and understand how nursing legal issues can affect them. Nurses must know the basic laws and avoid lawsuits and liability: Nursing is legally sensitive because it is the people's business. The nurse deals with people, safe nursing practice includes an understanding of the legal boundaries in which nurses must function. An understanding of the implication of the law supports critical thinking on the nurse's part. Laws are changing constantly to reflect changes in society, changes in the delivery of health care and advancement in medical technology. Nurses face legal issues daily. Issues may in connection to negligence, administering medication and advocating for the patient, the Nurse Practice Act lists all of the duties and role of a nurse, except the legal and ethical ones. If these duties and regulations are not followed, the nurse is at risk of losing his license and facing a Malpractice act. All these points keeping in mind the researcher felt the importance of the study.

The information booklet was an effective method in increasing the knowledge and improving the attitude of the staff nurses regarding legal responsibilities. The nurses found the information booklet, a very useful learning aid. They appreciated the booklet and expressed that the booklet was effective. It also helped them in learning many legal terms like tort, malpractice etc.

\section{REFERENCES}

1. Creighton, \& Helen.(1986). Law Every Nurse should know, $5^{\text {th }}$ Edition, Philadelphia: W.B Saunders company.

2. Cameron, \& M E. (1997). Legal and Ethical issues : Professional Boundaries in nursing" journal of professional Nursing, Vol. 13 (3) ,142-143.

3. Aveyard, H. (2010). European journal of Health Law, adolescent consent and confidentiality in the U.K. Dec; 16 (4 ,309-331.

4. Chole C. (2008). Handing over responsibilities Journal of Nursing standard, Vol.22 (3) 61.

5. Crigin, \& Marshal H.E. (2004). Ethical and Legal Issues in Conducting Nursing Research via the Internet", Journal of Professional Nursing, January- February Vol. 20 (1),68-73.

6. Prema P. (2009). Nursing and Medical students attitudes towards nursing disclosure of information of patients. journal of advanced Nursing , (1987) Vol. 12 , (10) 691-698.

7. Pauline, Muriel A. (1973). Accountability a professional imperative Nursing Outlook 21 (3). 154-158.

8. Sheila D., \& Finn A.N. (2008). Nursing record keeping journal of nursing, vol.17, (5) 326-327.

9. Barnbas's (2004). An Exploration of content of legal aspects of practice in nursing programme. Journal of Nursing Education, vol.38(9), 440

10. Warren, \& Judith, j. (1983). Accountability and Nursing Diagnosis The journal of nursing_administration, Vol.17 (17) 34-37. 